\title{
GESTÃO PARTICIPATIVA NO TERCEIRO SETOR EM ORGANIZAÇÕES CEARENSES
}

\author{
PARTICIPATORY MANAGEMENT IN THE THIRD SECTOR ORGANIZATIONS IN CEARÁ
}

Recebido em 23.04.2014. Aprovado em 07.10.2014

Avaliado pelo sistema double blind review

DOI: http://dx.doi.org/10.12712/rpca.v8i4.433

\section{Ana Rita Rogério Maia Nogueira \\ anamaia007@gmail.com \\ Universidade de Fortaleza -Fortaleza - CE - Brasil}

Fabiana Pinto de Almeida Bizarria

bianapsq@hotmail.com

Universidade de Fortaleza -Fortaleza - CE - Brasil

\section{Mônica Mota Tassigny}

monicatassigny@unifor.br

Universidade de Fortaleza -Fortaleza - CE - Brasil

\section{Resumo}

Esta pesquisa busca abordar a gestão participativa e sua aplicação na gestão destas organizações, apresentando as origens do conceito do terceiro setor, seu desenvolvimento e características. Objetiva-se responder a seguinte pergunta: a gestão em organizações não governamentais (ONGs) e em organizações da sociedade civil de interesse público (OSCIPs) é participativa? Utilizou-se a pesquisa de natureza fenomenológica-interpretativa e qualitativa. A coleta de dados foi realizada por meio de questionário semiestruturado, tendo como método a análise de conteúdo dos discursos dos entrevistados. 0 percurso teórico-empírico possibilitou a constatação de que existe participação por parte dos funcionários nas atividades, o que caracteriza uma busca da execução da gestão participativa, nas ONGs e OSCIPs pesquisadas.

Palavras-chave: Terceiro Setor. Participação. Gestão Participativa. Gestão Social.

\begin{abstract}
This research seeks to address participatory management and its application in the management of these organizations, presenting the origins of the concept of the third sector, its development and characteristics. It aims to answer the following question: management in nongovernmental organizations (NGOs) and civil society in the public interest (OSCIPs) organizations is participatory? We used the research of a phenomenological-interpretative and qualitative. Data collection was conducted through semi-structured questionnaire, with the method of content analysis of the interviews. The theoretical and empirical course enabled the
\end{abstract}




\section{Ana Rita Rogério Maia Nogueira, Fabiana Pinto de Almeida Bizarria e \\ Mônica Mota Tassigny}

realization that there is participation by employees in the activities, which characterizes a search of the implementation of participative management, NGOs and OSCIPs surveyed.

Keywords: Third Sector. Participation. Participative Management. Social management.

\section{Introdução}

As discussões recentes no campo da Ciência Política, tanto na esfera acadêmica quanto no âmbito das práticas sociais concretas, concede lugar de destaque ao chamado terceiro setor. Multiplicam-se as publicações, seminários e debates cujo foco é discutir a relevância, especificidades e natureza das organizações que atuam nesse campo.

O termo terceiro setor começou a ser utilizado nos Estados Unidos, a partir da década de 1970. Nos anos 1980, passou a ser adotado também na Europa. No Brasil, tal fato ocorreu na década de 1990 (COELHO, 2000).

Observa-se que uma das características do terceiro setor é sua extrema heterogeneidade, o que repercute na ausência de consenso quanto a abrangência de seu conceito e às terminologias adotadas para se referir às organizações que o compõem (COSTA JÚNIOR, 1998).

Atribui-se ao terceiro setor, uma gama variada de organizações que vão desde entidades sem fins lucrativos, instituições filantrópicas, fundações, projetos sociais vinculados a empresas, organizações não governamentais, dentre outros (CARRION, 2000).

A partir do estudo de análise de conteúdo do material coletado em ONGs e OSCIPs, este trabalho busca abordar a gestão participativa e sua aplicação na gestão destas organizações como tipo gestionário específico.

Os objetivos específicos desta pesquisa são:

b) compreender como a gestão participativa está inserida nas organizações do terceiro setor, sobretudo na administração das ONGs e das OSCIPs; e

c) analisar a contribuição da gestão participativa na tomada de decisão das ONGs e das OSCIPs.

Com arrimo no assunto em foco, foram consideradas os seguintes pressupostos:

a)a gestão participativa é o tipo gestionário apropriado à administração das organizações do terceiro setor: ONGs e OSCIPs;

b) as organizações do terceiro setor estão intermediando e ajudando a participação a se tornar real; e

c) a gestão participativa prioriza a participação nas discussões, decisões e execuções organizacionais.

A partir do exposto, elaborou-se a presente pesquisa, com o objetivo de responder à seguinte pergunta: a gestão em organizações não governamentais e em organizações da sociedade civil de interesse público é participativa?

O percurso metodológico do trabalho de campo seguiu a abordagem exploratória, descritiva e de natureza qualitativa, com suporte em entrevistas com cinquenta e seis pessoas vinculadas a ONGs e OSCIPs pertencentes ao universo desta pesquisa. Para o processo de análise das narrativas utilizou-se a análise de conteúdo.

\section{Terceiro setor}

A ideia terceiro setor é formulada a partir de um recorte do social em esferas: o Estado (primeiro setor), o mercado (segundo setor) e a sociedade civil (terceiro setor) (MONTAÑO, 
2002). Caracteriza-se como um fenômeno que envolve um número significativo de organizações e instituições, organizações não governamentais, sem fins lucrativos, instituições filantrópicas, entre outras.

A expressão terceiro setor que foi recortada no conjunto das ideias da economia clássica para a qual a sociedade é dividida em setores, de acordo com as finalidades econômicas dos agentes sociais, entendidos como agentes de natureza jurídica pública e agentes de natureza jurídica privada (WEISBROD, 1988).

O terceiro setor pode ser entendido como aquilo que é público, porém privado, ou então aquilo que é privado, porém público (FERNANDES, 1994). Essa concepção denota a complexidade e ambiguidade do conceito, visto que o público, porém privado, muitas vezes pode estar mais próximo do privado que do público, como é a caso de projetos sociais vinculados a grandes empresas; ou então, o privado, porém público, pode estar mais próximo do público, como é o caso de muitas organizações filantrópicas cujos recursos, metodologias e suporte originam-se quase na sua totalidade do estado (TEODÓSIO, 2002).

Esse trocadilho serve para demonstrar que o terceiro setor assemelha-se ao Estado (primeiro setor), na medida em que tem como objetivos e alvo de atuação o espaço público, mas diferencia-se do Governo por ser uma iniciativa da própria sociedade. Por outro lado, terceiro setor não equivale a iniciativa privada (segundo setor), pois apesar de não ser governamental, tem como objetivo o benefício social.

O terceiro setor é auxiliado e auxilia os outros dois setores (público e privado), formando um movimento que lembra, guardadas as devidas proporções, os freios e contrapesos que mantêm o equilíbrio entre as funções do Estado (PINHO, 2001). 0 terceiro setor quando auxilia o primeiro, na realização de objetivos sociais, e o segundo, ao permitir a elevação do nível econômico das pessoas. 0 terceiro setor é subsidiado por ambos os setores, na medida em que o Estado lhe fornece isenções tributárias e as empresas lhe destinam parte de sua receita, em troca das mesmas isenções concedidas pelo Estado.

As organizações do terceiro setor não fazem parte do Estado, nem a ele estão vinculadas, mas se revestem de caráter público, na medida em que se dedicam a causas e problemas sociais e em que, apesar de serem sociedades civis privadas, não têm como objetivo o lucro, e sim o atendimento das necessidades da sociedade (TENÓRIO, 2001).

$\mathrm{Na}$ abrangência do terceiro setor, encontram-se organizações de matizes diferentes. Alguns exemplos de organizações que podem ser definidas como pertencentes ao terceiro setor: associações comunitárias, organizações não governamentais, instituições filantrópicas, fundações, igrejas e seitas, organizações sociais, projetos sociais desenvolvidos por empresas, sindicatos, dentre outros (TEODÓSIO, 2001).

0 terceiro setor caracteriza-se por ser formado de "organizações estruturadas; localizadas fora do aparato formal do Estado; que não são destinadas a distribuir lucros auferidos com suas atividades, autogovernadas; e que envolvem indivíduos em um esforço voluntário." (SALAMON; ANHEIER, 1995, p. 52).

As organizações de terceiro setor também se caracterizam pela não-lucratividade como finalidade e que constroem estratégias centradas na busca de melhorias para a comunidade como um todo ou para grupos específicos da população (TEODÓSIO, 2001; MURARO; LIMA, 2003). Diante disso, consideram-se integrantes do terceiro setor organizações que vão desde fundações, com estruturas formais rígidas, e uma relação de proximidade com o Estado e grandes empresas, a movimentos sociais pouco estruturados, englobando grupos religiosos e associações de moradores. Pode-se afirmar, segundo os autores referidos há pouco, que o terceiro setor se compõe de: 


\section{Ana Rita Rogério Maia Nogueira, Fabiana Pinto de Almeida Bizarria e \\ Mônica Mota Tassigny}

- associação, que é uma organização voltada aos interesses dos próprios participantes, compreendendo uma grande variedade de objetivos e atividades recreativas, esportivas, culturais, artísticas, comunitárias e profissionais;

- organizações filantrópicas - beneficentes e de caridade - voltadas para a filantropia (assistencialismo a pobres, desvalidos, desfavorecidos, miseráveis, excluídos e enfermos). É composta por abrigos, orfanatos, centros para indigentes, organizações voltadas à distribuição de alimentos, vestuário, hospitais, creches, serviços sociais na área de saúde, educação, como colégios religiosos e universidades;

- organizações não governamentais - diferem das filantrópicas por não exercerem nenhum tipo de caridade, chegando até a se posicionar contra esta atitude. As organizações não governamentais lutam pelo direito e pela igualdade de todos. Normalmente, são iniciativas de pessoas ou grupos que visam a colaborar na solução de problemas da comunidade, como mobilizações, educação, conscientização e organização de serviços ou programas para o atendimento de suas necessidades, daí sua diferenciação das associações, por estarem voltadas a "terceiros", não buscando seus objetivos comuns; e

- fundações privadas - entidades sem fins lucrativos, que se formam pela constituição de um patrimônio com o objetivo de servir a fins públicos. A fundação se constitui quando tal patrimônio (geralmente doado) adquire personalidade jurídica e passa a ser destinado para consecução de seus objetivos. Trabalham também com várias finalidades - educação, saúde, qualidade de vida, dentre outras.

De acordo com a finalidade estas organizações dividem-se em dois grupos: (a) aquelas constituídas para atender os interesses de seus membros (member-serving organizations), como é o caso dos sindicatos, das associações profissionais, das associações de bairro e empresariais; e (b) organizações de interesse público ou coletivo, a exemplo de entidades que apoiam vítimas da discriminação, portadores de determinadas doenças ou deficiência física, instituições de caridade e organismos de proteção ao meio ambiente (RODRIGUES, 1999). Assim, o terceiro setor é composto de tipos organizativos variados, desde organizações de base comunitária, sindicatos, igrejas a hospitais e escolas (MELO et al., 2003).

Além das definições citadas, Terceiro setor é expressão bastante utilizada para caracterizar as organizações que atuam no domínio social (FERNANDES, 1994; FISHER; FALCONER, 1998). Tal concepção refere-se à natureza destas organizações que não pertencem ao aparelho burocrático do Estado nem ao conjunto das empresas privadas e demais instituições que compõem a economia de mercado. Portanto, cabe nesta definição um conjunto vasto de organizações que vão desde as organizações não governamentais, institucionalmente representadas pela Associação Brasileira de Organizações não Governamentais (ABONG), passando pelas fundações empresariais e institutos, que hoje constituem o Grupo de Instituições e fundações empresariais (GIFE), que realizam investimento social voluntário e sistemático, incluindo também as organizações populares, oriundas de iniciativas das comunidades, as cooperativas e os organismos internacionais de cooperação, que atuam como parceiros dos organismos locais e financiam inúmeros projetos no País.

A classificação em três setores na perspectiva de Najam (1996) e serve-se de metáfora do Príncipe, do Mercador e do Cidadão para demarcar três conjuntos de organizações. 0 primeiro desses conjuntos é formado de organismos estatais; o Príncipe, uma vez que cabe às organizações estatais manter a ordem social. Para atingir os seus objetivos, o Príncipe usa a autoridade legítima e a sanção coercitiva a ele delegada pela sociedade; o Príncipe representa os 
interesses da maioria (ou de grupos dominantes) e opera na esfera do sistema político. 0 segundo conjunto de organizações é identificado à figura do Mercador e corresponde ao mercado; as organizações, nesse conjunto, estão envolvidas nas atividades de produção de bens e serviços. 0 Mercador cumpre seus propósitos por meio de trocas econômicas negociadas e visa a maximizar lucros; representa os interesses individuais e opera na esfera do mercado.

O terceiro conjunto de organizações corresponde ao Cidadão, o setor associativo voluntário. As organizações classificadas neste último conjunto são as que mais se ocupam com articular e realizar visões sociais, atingem seus objetivos por meio de valores normativos partilhados entre os patronos, membros e beneficiários; nesse conjunto, representam-se interesses marginalizados que operam na esfera da sociedade (NAJAM, 1996).

Essa metáfora foi criada para estabelecer conjuntos heterogêneos, numa classificação escolhida por ser a mais abrangente possível, não fazendo qualquer tipo de distinção entre organizações, quer seja por tamanho, local, base financeira ou interesse substantivo (NAJAM, 1996). A teoria inclui países do Primeiro e do Terceiro Mundo. E é por ser muito inclusiva que a teoria de Najam (1996) não oferece mais do que um modo excessivamente simplificado de descrever e definir o fenômeno das organizações que não têm o lucro como único ou principal objetivo.

Outro ponto de vista se dá na discussão da lógica e dos processos pelos quais o conjunto expressivo terceiro setor é atribuído a diferentes organizações do setor não lucrativo (SMITH, 1991). Esta perspectiva parte do princípio de que quase todas as análises partem da ideia de que o mundo social é tripartite.

Porém, o principal 'erro' das teorias que se elaboram a partir desse enfoque está no fato de as teorias não considerarem a "quarta" categoria que há no mundo social: o setor doméstico (SMITH, 1991). Na literatura tradicionalmente aceita em Economia, o setor doméstico aparece associado ao setor privado (esfera do mercado), o que é um erro, porque o setor doméstico e o setor privado têm racionalidades e modos de ação diferentes. 0 doméstico envolve as relações familiares, de vizinhança e, deve ser considerado à parte, porque:

[...] envolve um número grande de pessoas interagindo de um modo distinto [...] que inclui ajuda mútua e informal, independente se as pessoas moram juntas. As pessoas envolvidas nesse modo são membros da família, vizinhos e, de forma mais restrita, conhecidos, colegas de trabalho, membros da comunidade e membros de grupos voluntários e outros contextos (SMITH, 1991, p. 138).

Ao demarcar o mundo doméstico como setor específico, Smith (1991) 'desloca' o mundo das organizações não lucrativas, do terceiro para o quarto lugar, e rearranja a ordem consagrada dos setores: mundo doméstico, mercado, Estado e setor não lucrativo. Nesse novo arranjo, o chamado terceiro setor deixa de ser a esfera privilegiada das ações de caráter voluntário, uma vez que pode haver serviço voluntário também no setor doméstico.

Seguindo a mesma linha de argumentação, também se defende a posição de que, para efeito de análise, se incluam as relações domésticas entre os setores da sociedade que provêem o bemestar (welfare provision) (BILLIS, 1993). Encontra-se aí o mundo doméstico, setor das relações domésticas, que se define como a parte da sociedade na qual "os problemas sociais são resolvidos por parentes, amigos, vizinhos em caráter particular.” (BILLIS, 1993, p. 11).

As relações nesse campo são quase sempre não explícitas, informais e, algumas vezes, são difíceis de caracterizar. 0 setor não lucrativo situa-se em outro mundo, o associativo, que tem intersecção com o mundo doméstico e com o das organizações burocráticas; este último, por sua vez, subdivide-se em burocracias governamentais e privadas (BILLIS, 1993). Embora o setor lucrativo se construa a partir de uma lógica basicamente associativa, algumas organizações 


\section{Ana Rita Rogério Maia Nogueira, Fabiana Pinto de Almeida Bizarria e \\ Mônica Mota Tassigny}

lucrativas estão situadas em zonas ambíguas, nas intersecções que há entre o mundo associativo, doméstico e o burocrático, o que confere a estas organizações um caráter ambíguo.

0 terceiro setor também é entendido como uma área que intermedeia o mercado, o Estado e a comunidade; uma dimensão do espaço público, que se observa em diversas sociedades civis e, portanto, mais uma área intermediária do que, propriamente, um setor definido (EVERS, 1995). "O terceiro setor deveria ser definido como um subespaço do espaço público nas sociedades civis, isso é, como um campo de tensão sem fronteiras muito definidas, no qual diferentes racionalidades e discursos coexistem e se interceptam". (EVERS, 1995, p. 161).

Nesse contexto, o movimento do terceiro setor no Brasil aparece como forma de dar conta dos novos valores que despontam num mundo global. 0 propósito principal das organizações do terceiro setor é maximizar os bens sociais que elas produzem para a sociedade e para as pessoas que delas participam. A ideia se torna popular, porque representa uma forma de responder à necessidade de mudanças em um ambiente, em que as formas tradicionais de lidar com os problemas sociais se mostram ineficazes.

Sendo assim, torna-se necessário discutir os papéis das organizações do terceiro setor, algumas formas de ação desenvolvidas por essas organizações que se encontram na ação da sociedade, na articulação, implementação e gestão participativa, a partir do cenário brasileiro.

\section{Gestão participativa}

Gerir é, em sua essência, tomar decisões, é o modo como a autoridade será distribuída e, consequentemente, como será exercido o controle, considerando que a responsabilidade é intrínseca ao poder assumido (FIGUEIREDO; CAGGIANO,1997).

Encontram-se na literatura diferentes estilos da gestão - participativa, centralizada, estatizada. Quando se pensa na gestão participativa, defronta-se com uma dificuldade inicial, relativa ao conceito e significado do que é participação. Na qualidade de um conceito central, a participação é a variável que define e indica o que e como alguém faz algo numa organização (MENDONÇA, 1987).

A expressão gestão participativa aufere maior impacto em empresas e organizações preocupadas com o aperfeiçoamento de suas estratégias da gestão. Nesse cenário, personagens como o patrão autoritário e o funcionário submisso saem de cena para dar lugar a uma nova forma de relação, mais democrática e produtiva, no ambiente de trabalho, porém a autoridade é imprescindível, mas tem que ser exercida sem autoritarismo.

A prática da gestão participativa pode resultar da iniciativa e de pressões dos trabalhadores, sendo desta forma uma conquista, na medida em que amplia a intervenção na questão do poder, da autoridade e do controle sobre o processo produtivo. De outro lado, pode resultar de estratégias gerenciais na busca de contornar os conflitos e atingir maior desenvolvimento dos trabalhadores, objetivando ganhos de produtividade.

A gestão participativa possui várias vantagens. Dentro de uma visão mais crítica, estas vantagens podem ser divididas, segundo o beneficiário (MOTTA, 1995):

- vantagens para o empresário - maior compreensão e aceitação das decisões pelos subordinados, maior comprometimento com a implementação de decisões e maior compreensão dos objetivos dos funcionários. Utilização de todo o potencial das pessoas, maior cumprimento das necessidades psicológicas, cooperação e coordenação dos funcionários nas áreas de trabalho, melhores meios de resolução construtiva de conflitos e melhores decisões; e 
- vantagens para o funcionário - maior satisfação, maior identidade, redução de alienação, diminuição de conflitos por intermédio da cooperação, modo mais democrático de administrar; busca satisfazer aspirações individuais de iniciativa e criatividade; assegura melhor integração e interação com o grupo organizacional.

Com efeito, entende-se que a gestão participativa, uma vez aplicada dentro de uma organização de maneira plena, correta e transparente, promoverá o consenso, a harmonia, a cooperação, além de otimizar a produtividade, a qualidade e a eficácia, fatores que, se acredita, preponderantes para a sobrevivência da organização.

Um conjunto de tendências paralelas vem fortalecendo a adoção do modelo da gestão participativa nas empresas como resposta às novas necessidades no âmbito capitalista, como a consolidação da democracia, a globalização da economia, em que as organizações estão saindo do isolamento para a integração e uma interdependência de fornecedores, clientes, empresários e funcionários (MCLAGAN; NEL, 2000). O estilo participativo de governar procura superar as práticas de gestão burocrática e tradicional, marcada pela centralidade administrativa (SOTERO, 2002).

Para buscar a superação de estilos de gestão burocrático e tradicional, surgiu a gestão participativa, com as seguintes características (SOTERO, 2002): estruturas colegiadas de gestão; lideranças populares com capacidade de formulação; gestão por projetos; e descentralização territorial. Além disso a gestão participativa é representada por quatro processos essenciais para sua caracterização: interdisciplinaridade, motivação, socialização e participação (LEITE et al., 2000).

Nas organizações do terceiro setor, o processo participativo contribui para que os sujeitos vivenciem a sua condição de cidadão e, mediante ações concretas nos seus espaços conquistados dentro da organização, aprendem noções do projeto de cidadania. Isso inclui a formação e a participação de ser um sujeito social, ter direitos e deveres, o estabelecimento da democracia, ter acesso à informação e ao saber e aos componentes culturais que o forjaram como um sujeito consciente e participativo da vida social e política de seu país.

\section{Metodologia}

A pesquisa é de natureza qualitativa exploratória e descritiva (MINAYO, 1994). 0 universo deste estudo contempla as organizações não governamentais e as organizações da sociedade civil de interesse público fiscalizadas pelo Ministério da Justiça e pela Associação Brasileira de Organizações não Governamentais (ABONG).

Foram selecionadas onze unidades organizacionais de um universo de dezenove organizações não governamentais cadastradas pela ABONG e noventa e uma OSCIPs cadastradas pelo Ministério da Justiça na cidade de Fortaleza, representando 10\% dentre as ONGs e OSCIPs.

Na escolha de dados, foram entrevistados cinquenta e seis pessoas das ONGs e das OSCIPs, dentre gestores, voluntários, estagiários e funcionários: 13 gestores da Diretoria Executiva; 9 voluntários; 5 estagiários - de Pedagogia, Biologia, Arquitetura, Engenharia e do Direito; e 29 funcionários, sendo dois auxiliares do setor de pessoal, três secretários executivos, quatro auxiliares administrativos, um de serviços gerais, um assessor técnico, um assessor de comunicação, uma assessora comunitária, um assessor jurídico, onze coordenadores de projetos, uma educadora infantil, dois técnicos ambientais e uma bióloga.

Os procedimentos metodológicos adotados seguem o ciclo da pesquisa social, dividida em três fases: a exploratória, o trabalho de campo e a análise ou tratamento do material (MINAYO, 


\section{Ana Rita Rogério Maia Nogueira, Fabiana Pinto de Almeida Bizarria e \\ Mônica Mota Tassigny}

1994). Caracterizando a fase exploratória da pesquisa, a autora diz que esta "é tão importante que ela em si pode ser considerada uma pesquisa exploratória”. (MINAYO, 1994, p. 89).

As técnicas utilizadas de coleta de dados foram as entrevistas realizadas por meio de questionário semiestruturado, o trabalho de campo e a observação. Os métodos de análise dos dados utilizados foram a análise interpretativa e de conteúdo (BARDIN, 1979). "A intenção da análise de conteúdo é a inferência de conhecimentos relativos às condições de produção (ou, eventualmente, de recepção), inferência esta que recorre a indicadores (quantitativos ou não)". (BARDIN, 1977, p. 38).

$\mathrm{Na}$ análise de conteúdo, utilizou-se a análise temática. A noção de tema está ligada a uma afirmação a respeito de determinado assunto. Comporta um feixe de relações e pode ser apresentada mediante uma palavra, uma frase, um resumo. "0 tema é a unidade de significação que se liberta naturalmente de um texto analisado segundo critérios relativos à teoria que serve de guia à leitura". (BARDIN, 1979, p. 105).

Fazer uma análise temática consiste em descobrir os núcleos de sentidos que compõem uma comunicação, cuja presença ou frequência signifiquem alguma coisa para o objetivo analítico visado; ou, ao contrário, qualitativamente a presença de determinados temas denota os valores de referência e o modelos de comportamento presentes no discurso (MINAYO, 1998).

Operacionalmente a análise temática desdobra-se em três etapas: a) a pré-análise; b) a descrição analítica ou exploração do material; e c) a fase de interpretação referencial ou tratamento dos resultados e interpretação (BARDIN, 1977).

A seguir, apresenta-se um quadro sintetizando a pesquisa:

\begin{tabular}{|c|c|c|c|c|}
\hline Org & Parcerias: & Corpo atuante: & Entrevistado & Público beneficiário: \\
\hline A & $\begin{array}{l}\text { Governo do } \\
\text { Estado, } \\
\text { Prefeitura de } \\
\text { Fortaleza } \\
\text { UECE, } \\
\text { UNIFOR, } \\
\text { UFC. }\end{array}$ & $\begin{array}{l}1700 \text { funcionários, } \\
600 \text { prestadores } \\
\text { de } \\
\text { serviços, } 10 \\
\text { estagiários } \\
(6 \mathrm{M}, 4 \mathrm{H}) \text { e } \\
6 \text { voluntários } \\
(4 \mathrm{M}, 2 \mathrm{H}) .\end{array}$ & $\begin{array}{l}1 \text { gestor e } 2 \\
\text { funcionários. }\end{array}$ & $\begin{array}{l}35.000 \text { pessoas da comunidade local do } \\
\text { bairro João Arruda. }\end{array}$ \\
\hline B & $\begin{array}{l}\text { Governo do } \\
\text { Estado. }\end{array}$ & $\begin{array}{l}\text { Não possui } \\
\text { registro }\end{array}$ & $\begin{array}{l}1 \text { gestor e } \\
1 \text { voluntário. }\end{array}$ & $\begin{array}{l}\text { Adolescentes e jovens da comunidade } \\
\text { situada em Maraponga. Não possui } \\
\text { registro da quantidade dos beneficiários. }\end{array}$ \\
\hline $\mathrm{C}$ & $\begin{array}{l}\text { Associações } \\
\text { comunitárias, } \\
\text { UNESCO. }\end{array}$ & $\begin{array}{l}7 \text { estagiários }(5 \mathrm{M}, \\
2 \mathrm{H}) \text { e } \\
14 \text { voluntários } \\
(8 \mathrm{M} \text { e } 6 \mathrm{H})\end{array}$ & $\begin{array}{l}1 \text { gestor, } \\
1 \text { voluntário e } \\
1 \text { estagiário. }\end{array}$ & $\begin{array}{l}\text { Classe trabalhadora e crianças da } \\
\text { comunidade rural da cidade de Fortaleza, } \\
\text { Icapuí, Maracanaú e } \\
\text { Maranguape. Não possui registro da } \\
\text { quantidade dos beneficiários. }\end{array}$ \\
\hline $\mathrm{D}$ & $\begin{array}{l}\text { Banco do } \\
\text { Nordeste. }\end{array}$ & $\begin{array}{l}\text { Cerca de } 1500 \\
\text { funcionários. }\end{array}$ & $\begin{array}{l}1 \text { gestor e } \\
1 \text { funcionário. }\end{array}$ & $\begin{array}{l}\text { Classe trabalhadora de baixa renda em } \\
\text { toda a região nordeste. Não possui } \\
\text { registro do público beneficiário. }\end{array}$ \\
\hline $\mathrm{E}$ & Ministério do & 9 funcionários & 1 gestor, & 1.700 famílias do município de Crateús \\
\hline
\end{tabular}




\begin{tabular}{|c|c|c|c|c|}
\hline & $\begin{array}{l}\text { meio } \\
\text { ambiente. }\end{array}$ & $\begin{array}{l}(6 \mathrm{H}, 3 \mathrm{M}), \\
4 \text { prestadores de } \\
\text { serviços }(3 \mathrm{M}, 1 \mathrm{H}) \text {, } \\
3 \text { estagiários }(2 \mathrm{M}, \\
1 \mathrm{H}) \text { e } \\
10 \text { voluntários } \\
(6 \mathrm{M}, 4 \mathrm{H}) .\end{array}$ & $\begin{array}{l}1 \text { estagiário e } \\
4 \\
\text { funcionários. }\end{array}$ & \\
\hline $\mathrm{F}$ & $\begin{array}{l}\text { Fórum pela } \\
\text { educação da } \\
\text { praia do } \\
\text { Futuro, outras } \\
\text { Ongs. }\end{array}$ & $\begin{array}{l}13 \text { funcionários } \\
(10 \mathrm{M}, 3 \mathrm{H}), \\
2 \text { prestadores de } \\
\text { serviços }(1 \mathrm{~F}, 1 \mathrm{M}) \text {, } \\
4 \text { estagiários }(2 \mathrm{M} \\
\text { e } 2 \mathrm{H}) \text { e } \\
1 \text { voluntário }(\mathrm{M}) .\end{array}$ & $\begin{array}{l}1 \text { gestor, } \\
1 \text { estagiário e } \\
2 \\
\text { funcionários. }\end{array}$ & $\begin{array}{l}\text { Crianças e adolescentes do } \\
\text { município de Ibicuitinga e Sobral. } \\
\text { Não possui registro do público } \\
\text { beneficiado. }\end{array}$ \\
\hline $\mathrm{G}$ & $\begin{array}{l}\text { USAID - } \\
\text { Agência } \\
\text { alemã, } \\
\text { Wobber } \\
\text { Windpower } \\
\text { Enecon - } \\
\text { empresa } \\
\text { alemã, } \\
\text { Governo do } \\
\text { Estado, } \\
\text { Sebrae-CE. }\end{array}$ & $\begin{array}{l}14 \text { funcionários } \\
(9 \mathrm{H} \text { e } 5 \mathrm{M}), \\
5 \text { prestadores de } \\
\text { serviços ( } 3 \mathrm{H} \mathrm{e} \\
2 \mathrm{M}), \\
\text { nenhum estagiário } \\
\text { e } 1 \text { voluntário }(\mathrm{H}) \text {. }\end{array}$ & $\begin{array}{l}1 \text { gestor, } \\
1 \text { voluntário e } \\
6 \\
\text { funcionários. }\end{array}$ & $\begin{array}{l}\text { Público beneficiário: } 3.500 \text { famílias } \\
\text { pertencentes à comunidade rural dos } \\
\text { municípios de Itapipoca, Trairí e } \\
\text { Pentecostes. }\end{array}$ \\
\hline $\mathrm{H}$ & $\begin{array}{l}\text { Instituição } \\
\text { francesa - } \\
\text { Fundation } \\
\text { Abbé Pierre, } \\
\text { UFC, FUNAI, } \\
\text { DNOCs, } \\
\text { MDA. }\end{array}$ & $\begin{array}{l}8 \text { funcionários } \\
(5 \mathrm{M} \text { e } 3 \mathrm{H}), \\
1 \text { prestador de } \\
\text { serviços }(\mathrm{H}), \\
6 \text { estagiários (4M } \\
\text { e } 2 \mathrm{H}) \text { e nenhum } \\
\text { voluntário. }\end{array}$ & $\begin{array}{l}1 \text { gestor, } \\
2 \text { estagiários } \\
\text { e } \\
1 \text { funcionário. }\end{array}$ & $\begin{array}{l}\text { Em torno de } 30.000 \text { pessoas das } \\
\text { comunidades de Tapeba e Alto Alegre }\end{array}$ \\
\hline I & $\begin{array}{l}\text { INCRA, } \\
\text { Banco do } \\
\text { Nordeste, } \\
\text { Caixa } \\
\text { Econômica, } \\
\text { Sebrae-CE. }\end{array}$ & $\begin{array}{l}7 \text { funcionários } \\
(\mathrm{M}), \\
30 \text { prestadores de } \\
\text { serviços (20M e } \\
10 \mathrm{H}), \\
1 \text { estagiário }(\mathrm{H}) \mathrm{e} \\
12 \text { voluntários }(8 \mathrm{H}\end{array}$ & $\begin{array}{l}1 \text { gestor, } \\
2 \text { voluntários } \\
\text { e } \\
7 \\
\text { funcionários. }\end{array}$ & $\begin{array}{l}500 \text { pessoas da comunidade rural nos } \\
\text { municípios do sertão central cearense. }\end{array}$ \\
\hline
\end{tabular}




\begin{tabular}{|c|c|c|c|c|}
\hline & & e 4M). & & \\
\hline $\mathrm{J}$ & $\begin{array}{l}\text { Prefeitura de } \\
\text { Fortaleza, } \\
\text { Banco do } \\
\text { Nordeste, } \\
\text { Sindicato dos } \\
\text { Trabalhadores } \\
\text { Rurais, } \\
\text { Central Única } \\
\text { dos } \\
\text { Trabalhadores } \\
\text { (CUT). }\end{array}$ & $\begin{array}{l}30 \text { funcionários } \\
(17 \mathrm{M} \text { e } 13 \mathrm{H}) \text {, } \\
4 \text { prestadores de } \\
\text { serviços ( } 3 \mathrm{M} \mathrm{e} \\
1 \mathrm{H}), 1 \text { estagiário } \\
(\mathrm{M}) \text { e } \\
1 \text { voluntário (M). }\end{array}$ & $\begin{array}{l}3 \text { gestores, } \\
1 \text { voluntário e } \\
6 \\
\text { funcionários. }\end{array}$ & $\begin{array}{l}\text { Em torno de } 7.496 \text { pessoas que são os } \\
\text { pequenos produtores rurais, pescadores } \\
\text { artesanais e artesãos em Itapipoca e } \\
\text { Quixeramobim. }\end{array}$ \\
\hline $\mathrm{L}$ & $\begin{array}{l}\text { Governo } \\
\text { Federal, } \\
\text { Instituições } \\
\text { nacionais e } \\
\text { internacionais. }\end{array}$ & $\begin{array}{l}14 \text { funcionários } \\
(9 \mathrm{M} \text { e } 5 \mathrm{H}) \text {, } \\
\text { nenhum prestador } \\
\text { de serviço, } \\
2 \text { estagiários ( } 2 \mathrm{M}) \\
\text { e } 4 \text { voluntários } \\
\text { (3M e } 1 \mathrm{H}) .\end{array}$ & $\begin{array}{l}1 \text { gestor e } \\
3 \text { voluntários }\end{array}$ & $\begin{array}{l}\text { Em torno de } 5.000 \text { pessoas do movimento } \\
\text { popular urbano da } \\
\text { cidade de Fortaleza. }\end{array}$ \\
\hline
\end{tabular}

Quadro 1. Síntese da pesquisa.

Fonte: Pesquisa direta.

\section{Análise inter organizacional da gestão das ONGS e OSCIPS: uma perspectiva da gestão participativa}

As dez categorias temáticas sobre caraterísticas de gestão são: Participação ativa dos membros da organização na tomada de decisão; Motivação para o trabalho; Ideal compartilhado entre todos os membros da organização; A auto-realização dos membros da organização; Identificação dos voluntários com a missão organizacional; Cooperação entre os membros da organização; A informalidade na organização; Trabalho voluntário; Solidariedade; Gestão voltada para o social),

As mais citadas foram: uma gestão voltada para o social, ideal compartilhado entre todos os membros da organização, solidariedade, a auto-realização dos membros da organização, cooperação entre os membros da organização e informalidade na organização. Características essenciais para se executar uma gestão participativa.

Pelas entrevistas, constatou-se que a variável mais significativa é a gestão voltada para o social com suporte na gestão participativa. Os entrevistados relataram que esta gestão está presente na organização, visto que uma das principais áreas de atuação de todas as instituições pesquisadas é a cidadania. A variável auto-realização dos membros da organização também é significativa, visto que a maioria dos entrevistados se sente realizada e feliz por atuar em instituições que têm na sua base e formação o compromisso com a coletividade.

A maioria dos entrevistados comentou que tem um mesmo ideal compartilhado entre si, por saber que o resultado do seu trabalho irá ajudar uma determinada população ou comunidade. A 
solidariedade também está presente nestas organizações, visto que os entrevistados relataram que a cooperação está mais presente do que a competição, pois o intuito da organização é trabalhar coletivamente em benefício da sociedade; embora alguns dos entrevistados tenham dito que às vezes não há o compartilhamento de informações, pois alguns querem se sobressair mais que outros.

A informalidade é também significativa na organização, pois uma das principais formas de comunicação utilizadas para transmitir as informações é "boca a boca". Uma, das onze organizações pesquisadas, não possui registro do corpo atuante e quatro, das onze, não possui registro da quantidade dos beneficiados. No que diz respeito à participação ativa dos membros da organização na tomada de decisão, a maioria comentou que quem participa das tomadas de decisão é a diretoria e a coordenação executiva. Em relação à identificação dos voluntários com a missão organizacional, a maioria do corpo atuante não conhece a missão de sua instituição de trabalho.

Observou-se que um dos aspectos dificultadores nessa análise é que o conceito de terceiro setor abrange uma multiplicidade de organizações, com diferentes trajetórias históricas, níveis de legitimidade social, formatos organizacionais, aporte de recursos e técnicas gerenciais. Entre as organizações pesquisadas, algumas instituições são pouco estruturadas, não adotando regras elementares da gestão de recursos humanos, como registro de seu corpo de funcionários, voluntários, estagiários ou prestadores de serviços. Outras instituições são estruturadas, adotando técnicas da gestão de recursos humanos importadas de empresas privadas.

\section{Contextualização da gestão das organizações do terceiro setor}

Constatou-se, pelas entrevistas, que nem todas as informações das organizações são compartilhadas por meio do gestor para todos os membros da Instituição, pois, dependendo da complexidade do problema, as informações se concentram mais no âmbito dos coordenadores. Em relação aos estagiários, voluntários e prestadores de serviços, as informações ocorrem de maneira indireta e específica. Consequentemente, na maioria das vezes, quem participa ativamente das tomadas de decisões são os coordenadores dos projetos e os gestores da Diretoria Executiva. Isso dificulta, segundo os voluntários, a atuação da organização.

Queria participar das reuniões, pois conheço melhor as necessidades da comunidade do que a diretoria. Moro nesta comunidade e sei muito bem dos seus problemas. (Voluntária).

Sou estagiário de arquitetura, vim trabalhar numa ONG no intuito de poder participar mais das resoluções dos problemas de uma instituição. Mas infelizmente só participo às vezes das reuniões e nem todas as informações são compartilhadas. As decisões concentram-se na diretoria executiva e nos coordenadores de projetos. (Estagiário de arquitetura).

A participação de todos os membros (voluntários, funcionários, estagiários ou prestadores de serviços) é de fundamental importância para a concretização da atuação das ONGs e das OSCIPs, pois, conforme as entrevistas, que eles estão muito mais presentes no dia-a-dia do público beneficiado do que o próprio gestor. Este, normalmente, não vai diariamente à Instituição, pois trabalha muito tempo fora da Organização, tentando realizar parcerias com os órgãos governamentais ou com instituições privadas, em sua maioria. Dessa forma, percebe-se a relevância da execução da gestão participativa em organizações do terceiro setor.

Ás vezes, me sinto desestimulada, sem capacidade para ajudar a resolver os problemas devido o autoritarismo do chefe. (Auxiliar do setor pessoal).

No que concerne à motivação para o trabalho de uma entidade do terceiro setor, pergunta exclusiva para os membros da organização, dos quarenta e três entrevistados, não incluindo os gestores, 20, isto é, $46 \%$, disseram que não são motivados pelos gestores. 0 gestor da instituição 


\section{Ana Rita Rogério Maia Nogueira, Fabiana Pinto de Almeida Bizarria e \\ Mônica Mota Tassigny}

tem mais contato com os coordenadores de projetos, não estabelecendo muitos vínculos com os demais membros da organização.

O estímulo por parte do gestor ocorre mais junto aos coordenadores, que são chamados para participar das reuniões e dos momentos de planejamento, podendo intervir e opinar. (Coordenador de Projetos).

\section{A motivação dos membros das ONGs e das OSCIPs}

Sinto-me desmotivado para trabalhar nesta organização, pois tenho pouco contato com o gestor, tenho muitas responsabilidades e poucas oportunidades para me expressar e participar. (Voluntário).

Embora se verifique a necessidade de maior participação e motivação dos membros nas ONGs e nas OSCIPs, dos cinquenta e seis entrevistados nesta pesquisa, apenas doze comentaram que não se sentem realizados em trabalhar na Instituição. A maioria dos entrevistados gosta muito do trabalho que está executando e sente que está contribuindo para uma transformação social do cidadão; estão satisfeitos com o clima organizacional, mesmo constatando que há rivalidades, algumas vezes, mas que se chega ao bom senso e termina prevalecendo a cooperação, pois a maioria tem um mesmo ideal compartilhado e voltado para a contribuição social e o benefício coletivo.

No que diz respeito à prática social e à política das ONGs e das OSCIPs, a maioria dos entrevistados comentou que, após a execução dos projetos sociais e finalizações dos convênios, o Estado abandona a causa social, e que, embora as organizações sejam reconhecidas pelas suas ações, a burocracia estatal dificulta a realização de convênios.

Fizemos o projeto social e conseguimos fazer um convênio com o Governo do Estado, que se mostrou muito interessado no início, mas logo depois não nos deu mais atenção, não havendo um acompanhamento. (Gestor da Diretoria Executiva).

As principais dificuldades que as ONGs e as OSCIPs enfrentam envolvem: falta de envolvimento do Poder público em alguns projetos sociais; ausência de planejamento estratégico; de articulação em parcerias com outras instituições; a burocracia e a demora para que um determinado projeto seja aprovado; o imediatismo dos resultados; a difícil conscientização do público beneficiário em permanecer em um curso, em uma capacitação; a falta de credibilidade da população e dos beneficiados no início das atividades; a ausência de incentivos financeiros das empresas privadas; a precariedade de recursos financeiros e humanos e o espaço físico, que, algumas vezes, é inapropriado para o desenvolvimento de atividades a que se propõem organizar.

Há uma difícil mudança de atitude em relação à proteção ao meio ambiente. Há uma falta de compromisso do Governo, do público beneficiário e da população em geral. (Secretária Executiva).

A maioria dos entrevistados disse que existem momentos em que as instituições funcionam como uma empresa, pois ressaltaram que possuem as mesmas obrigações no momento das prestações de contas, no sentido de terem que pagar impostos e encargos, e da responsabilidade com relação à eficiência da gestão dos recursos doados de terem que apresentar os resultados.

Todas as organizações pesquisadas possuem missão institucional, que, segundo os entrevistados, reflete o papel da entidade na sociedade em que atua. Das onze instituições pesquisadas, no entanto, apenas em uma organização os entrevistados souberam falar sobre a missão; nas demais, nem os gestores conseguiram se reportar a elas. 0 motivo alegado é o fato 
de a missão ser muito extensa, não dando para ser memorizada. Pode-se perceber, nesta alegação, o descaso como é tratado o documento que expressa o objetivo maior de cada instituição, ou seja, pode-se inferir que a missão não é debatida entre aqueles que a constituem.

Constatou-se que muitos são os benefícios sociais ensejados por estas organizações, como: favorecimento da construção e emancipação de agentes econômicos dos setores populares; fortalecimento do potencial organizativo das comunidades; melhorias das condições de habitação no espaço urbano e rural para as famílias de baixa renda; fortalecimento da agricultura familiar; promoção da economia solidária; concessão de créditos com baixos juros à população mais carente; proteção ao meio ambiente; reivindicação, junto aos órgãos públicos, dos direitos da criança e do adolescente; valorização do capital humano; promoção da cidadania; elevação da autoestima da população beneficiada; alfabetização de jovens e adultos; contribuição para os jovens se inserirem no mercado de trabalho por meio da capacitação profissional do fornecimento de cursos e palestras, dentre outros.

A população precisa se conscientizar e reconhecer o trabalho que algumas organizações do terceiro setor prestam em benefício à sociedade, não podemos ficar de braços cruzados nos conformando com tudo o que está acontecendo. (Voluntária).

Percebeu-se também que há muita informalidade nas ONGs e nas OSCIPs. A principal forma de comunicação utilizada para transmitir as informações é no "boca a boca". Além disso, algumas instituições não possuem registro do número de membros (corpo atuante) nem da quantidade do público beneficiário. Boa parte das entidades não possui planejamento estratégico, não têm registradas as pautas das reuniões nem o controle dos resultados.

Um dos maiores problemas que enfrentamos é a falta de planejamento estratégico e a falta de uma cultura para desenvolver ações de médio e longo prazos. (Coordenador de Projetos).

A gestão atualmente nas ONGs e nas OSCIPs é um pouco centralizadora. Parte da equipe pode sugerir e opinar nas reuniões, mas a tomada de decisão é dos gestores. Este se comunica mais com os coordenadores de projetos, ficando distantes do restante dos membros. Sua atuação é associada ainda ao conceito de "chefe", ficando em uma sala separada, onde, na maioria das vezes, não dá para ser visto. Há a necessidade de maior profissionalização e capacitação dos gestores no que diz respeito aos recursos humanos, em benefício de um melhor relacionamento e maior envolvimento deste com os demais membros e com o público beneficiário.

0 gestor tem um perfil bem empresarial com valores voltados para uma lógica pragmática e focada nos resultados. (Voluntária).

Há a presença de uma lógica excessivamente técnica e econômica, ocasionalmente assumida na organização por influência do perfil do gestor que é focado nos resultados. (Auxiliar Administrativo).

Dentre as variáveis mais citadas (características da gestão presentes na organização), encontrase uma gestão voltada para o social, solidariedade, a auto-realização e a cooperação entre os membros da organização, ideal compartilhado entre todos e informalidade na organização características essenciais para se executar uma gestão participativa.

Constatou-se que existem elementos essenciais da gestão participativa na execução das atividades das instituições colaboradoras, mesmo que na maioria delas, não haja participação de todos os membros nas tomadas de decisões, pois estas são mais gerenciais; e existem, em alguns casos, reflexos de autoritarismo do gestor e forte hierarquia. Os entrevistados comentaram que, em algumas das organizações pesquisadas, o gestor não é tão comprometido e é mais voltado para interesses pessoais.

É necessário que se tenha uma gestão mais descentralizada, em que se encontre uma maior 


\section{Ana Rita Rogério Maia Nogueira, Fabiana Pinto de Almeida Bizarria e \\ Mônica Mota Tassigny}

participação de todos. (Assessor de Comunicação).

\begin{tabular}{|c|c|c|}
\hline Objetivos & $\begin{array}{l}\text { Pressuposto } \\
\text { S }\end{array}$ & Reflexões sobre o fenômenos social estudado \\
\hline $\begin{array}{l}\text { Objetivo } \\
\text { Compreender } \\
\text { como a gestão } \\
\text { participativa } \\
\text { está inserida } \\
\text { nas } \\
\text { organizações } \\
\text { do terceiro } \\
\text { setor, } \\
\text { sobretudo na } \\
\text { administração } \\
\text { das ONGs e das } \\
\text { OSCIPs }\end{array}$ & $\begin{array}{l}\text { As } \\
\text { organizações } \\
\text { do terceiro } \\
\text { setor estão } \\
\text { intermediand } \\
\text { o e ajudando } \\
\text { a } \\
\text { participação } \\
\text { a se tornar } \\
\text { real. }\end{array}$ & $\begin{array}{l}\text { Observou-se por meio da presente pesquisa, que, de acordo com a } \\
\text { missão organizacional e para que se concretize aquilo que é proposto, } \\
\text { as organizações do terceiro setor intermedeiam e ajudam a } \\
\text { participação a se tornar real; mas, essa participação ainda não é } \\
\text { efetivada de maneira plena, pois na maioria das ONGs e OSCIPs } \\
\text { pesquisadas o público beneficiário não participa das reuniões e dos } \\
\text { planejamentos. Além disso, muitos dos voluntários, estagiários e } \\
\text { funcionários nem sempre têm oportunidades para se expressar e } \\
\text { participar. Concluiu-se que se faz necessária maior efetivação da } \\
\text { gestão participativa por parte dos gestores dessas instituições para a } \\
\text { concretização de uma gestão social plena. }\end{array}$ \\
\hline $\begin{array}{l}\text { Objetivo } \\
\text { Analisar a } \\
\text { contribuição } \\
\text { da gestão } \\
\text { participativa } \\
\text { na tomada de } \\
\text { decisão das } \\
\text { ONGs e das } \\
\text { OSCIPs. }\end{array}$ & $\begin{array}{l}\text { A gestão } \\
\text { participativa } \\
\text { prioriza o } \\
\text { processo de } \\
\text { participação } \\
\text { nas } \\
\text { discussões, } \\
\text { decisões e } \\
\text { execuções } \\
\text { organizaciona } \\
\text { is. }\end{array}$ & $\begin{array}{l}\text { Embora não seja ainda plena a gestão participativa nestas } \\
\text { organizações, mas é por meio deste tipo gestionário que existe maior } \\
\text { grau de participação dos membros nas decisões organizacionais, por } \\
\text { ser uma gestão social e em razão dos seus objetivos propostos. Por } \\
\text { meio desta pesquisa, observou-se que, na maioria das ONGs e OSCIPs } \\
\text { pesquisadas, nem todas as informações são compartilhadas e que as } \\
\text { decisões se concentram na Diretoria Executiva e nos coordenadores } \\
\text { de projetos. Os gestores têm pouco contato com os demais membros } \\
\text { da Instituição, resultando em desmotivação da equipe, que, apesar } \\
\text { disso, se sente, em sua maioria, auto-realizada. Mesmo assim, as ONGs } \\
\text { e OSCIPs, que são organizações do terceiro setor, caracterizam-se por } \\
\text { uma gestão participativa acima das existentes nas organizações dos } \\
\text { outros dois setores: o público e o privado. }\end{array}$ \\
\hline
\end{tabular}

Quadro 2 - Identificação da associação dos objetivos, junto às hipóteses e reflexões da pesquisa sobre o fenômeno social estudado.

Fonte: pesquisa direta

\section{Considerações finais}

A contextualização delineada no início desta etapa final do percurso teórico-empírico faz-se necessária, pois o propósito da presente investigação é propiciar uma análise crítica que contribua para uma ciência substantiva e democrática. Não são comuns contextualizações nas conclusões de trabalhos científicos, mas se entende aqui que as correntes teóricas de pensamento precisam ser retroalimentadas, bem como as práticas identificadas pela incursão no campo social. 0 presente trabalho objetivou abordar a gestão participativa e sua aplicação na gestão das ONGs e OSCIPs. A questão central formulada foi: a gestão em organizações não governamentais e em organizações da sociedade civil de interesse público é participativa?

Há evidências, pela análise da experiência das instituições pesquisadas, que as ONGs e OSCIPs executam uma gestão participativa, pois necessitam de um tipo gestionário específico, de uma gestão social, para a concretização de suas finalidades, que são voltadas para a transformação social. A gestão participativa, porém, não é executada de maneira plena, visto que, na maioria das entidades, não há participação de todos os membros nas tomadas de decisões, pois estas são mais gerenciais e existem, em alguns casos, reflexos de autoritarismo do gestor e uma hierarquia muito forte. 
Em tese, contudo, verificou-se neste estudo que é a gestão participativa a que mais pode se adequar como tipo gestionário organizacional do terceiro setor.

Logo, a gestão participativa é o tipo gestionário ideal das organizações do terceiro setor, priorizando a participação nas discussões, decisões e execuções organizacionais e as características do terceiro setor, mencionadas de acordo com a análise realizada nesta pesquisa.

O presente estudo teórico-empírico propiciou reflexões propositivas e um debate construtivo. As ONGs e OSCIPs precisam gerenciar a área social de forma descentralizada e intensamente participativa, estruturando uma visão comunitária e originando capital social. A pesquisa demonstra que algumas das ONGs e OSCIPs pesquisadas perdem a oportunidade da cooperação cívica e da formação efetiva de capital social. Verifica-se, ainda, certa nebulosidade quanto às suas características, marco legal de âmbitos de atuação, porém iniciou-se uma discussão a respeito da gestão das organizações do terceiro setor, que se adapte melhor à administração das empresas deste, e, conforme foi visto, não são públicas nem privadas, mas têm características singulares, que as situam em um setor específico.

Os espaços para uma participação, como ato e processo político na conquista e ocupação de espaços de poder nas organizações estudadas deste setor, ainda demandam um maior entendimento por parte da direção e dos funcionários, em que os sujeitos vão se apropriando dos espaços conquistados pelo compromisso, envolvimento e presença.

Algumas das ONGs e OSCIPs pesquisadas praticam uma gestão controlada de recursos comunitários no atendimento às respostas concretas e demandas contingentes e individualizadas. Por meio desta prática, o Governo descentraliza a execução da política social, repassa dinheiro público e define qual organização parceira executará a ação social e, só então, a comunidade se mobiliza e participa em ações já estabelecidas pelo poder instituído. Mesmo assim, muitos são os benefícios sociais ocasionados pelas instituições do terceiro setor. Compreende-se que a sociedade civil constitui espaço privilegiado das lutas de classe e sociais pela hegemonia.

No que diz respeito aos beneficiados das organizações estudadas e pesquisadas, como pertencentes ao terceiro setor, seriam necessárias maior inserção e a utilização de mecanismos e canais para ouvir e sistematizar a sua vez e voz como representantes e parceiros externos destas organizações.

Para finalizar, ressalta-se que cidadania e transformação social são conceitos profundamente ligados à ideia de participação. Para a emergência desta ação, capaz de levar ao alcance da cidadania, é fundamental o compromisso das organizações na preparação das pessoas para esse processo. Para tanto, é necessário possibilitar o acesso aos recursos necessários e favorecer formas coletivas de solução de problemas.

\section{Referências}

BARDIN, L. Análise de Conteúdo. Lisboa: Edições 70, 1977.

BARDIN, L. Análise de Conteúdo. Lisboa: Edições 70, 1979.

BILLIS, D. Organising Public and voluntary agencies. London: Routledge, 1993.

CARRION, R. M. Organizações privadas sem fins lucrativos: a participação do mercado no terceiro setor. Tempo Social; Revista da Sociologia da USP. São Paulo: v. 12, n. 2, nov. 2000.

CARRION, R.; GARAY, Â. Organizações privadas sem fins lucrativos: a 


\section{Ana Rita Rogério Maia Nogueira, Fabiana Pinto de Almeida Bizarria e \\ Mônica Mota Tassigny}

participação do mercado no terceiro setor. Porto Alegre: Análise, v.12, 2000.

CARVALHO, N. V. O terceiro sujeito: um novo ator para um velho cenário. In: DOWBOR, L. et al. Desafios da globalização. Petrópolis, RJ: Vozes, 1997, p. 199-214.

COELHO, S. Terceiro setor: um estudo comparado entre Brasil e Estados Unidos. São Paulo: SENAC, 2000.

COSTA JÚNIOR, L. C. Caderno do III setor - terceiro setor e economia social. São Paulo: Fundação Getúlio Vargas/Escola de Administração de Empresas de São Paulo, n. 2, abr. 1998.

EVERS, A. "Part of the Welfare Mix: the third sector as an intermediate area":

Voluntas, v. 6, n. 2, p. 159-82, 1995.

FERNANDES, R. C. Privado porém público: o terceiro setor na América Latina. Rio de Janeiro: Relume-Dumará, 1994.

FIGUEIREDO, S.; CAGGIANO, P. C. Controladoria: teoria e prática. São Paulo: Atlas, 1997

FISHER; FALCONER A. "Desafios da parceria governo e terceiro setor". Revista de

Administração - USP. São Paulo, v. 33, n. 1, 1998.

IOSCHPE, E. B. et al. Terceiro Setor: desenvolvimento social sustentado. In:

ENCONTRO IBERO-AMERICANO DO TERCEIRO SETOR, III, 2000.Rio de Janeiro. Anais... Rio de Janeiro: Paz e Terra, 2000. 1 CD-ROM.

LEITE, F. T. et al. Por uma Teoria da Gestão Participativa: um novo paradigma de administração para o século XXI. Coletânea. Fortaleza: UNIFOR, 2000.

McLAGAN, P.; NEL, C. A Nova Era da Participação. Rio de Janeiro: Campus, 2000.

MELO, V. P; FISCHER, T.; SOARES JUNIOR, J. S. Diversidades e confluências no campo do terceiro setor: um estudo de organizações baianas. In:

ENCONTRO ANUAL DA ASSOCIAÇÃO NACIONAL DE PÓS-GRADUAÇÃO EM ADMINISTRAÇÃO-ENANPAD, XXVII; 2003, Atibaia-SP. Anais... Atibaia: ANPAD, 2003.1 CD-ROM.

MENDONÇA, L. C. de. Participação na organização: uma introdução aos seus fundamentos, conceitos e formas. São Paulo: Atlas, 1987.

MINAYO, M. C. de S. O desafio do Conhecimento: pesquisa qualitativa em saúde. 3. ed. São Paulo: Hucitec, 1994.

MONTAÑO, Carlos. Terceiro setor e questão social: crítica ao padrão emergente de intervenção social. São Paulo: Cortez, 2002.

MURARO, P.; LIMA, J. E. S. Terceiro setor, qualidade ética e riqueza das

organizações. Rev. FAE, Curitiba, v.6, n. 1, p. 88-79, jan./abr. 2003.

NAJAM, A. Understanding the third sector: revisiting the prince, the marchand and the citizen. Nonprofit management and leadership, v. 7, n. 2, p. 203-19, 1996.

PAULA, A. P. P. Um estudo de caso da Associação Brasileira de Organizações Não

Governamentais: construindo uma nova gestão pública em espaços públicos alternativos. In: ENCONTRO ANUAL DA ASSOCIAÇÃO NACIONAL DOS PROGRAMAS DE PÓSGRADUAÇÃO EM ADMINISTRAÇÃO-ENANPAD, XXI; 1997. Rio das Pedras, Angra dos Reis - RJ: Anais... Rio das Pedras, Angra dos Reis:ANPAD, 1997 - 1 CD-ROM. 
PINHO, H. D. B. A natureza jurídica do direito individual homogêneo e sua tutela pelo ministério público como forma de acesso à justiça. Rio de Janeiro: Forense, 2001.

SALAMON, L.; ANHEIER, H. Partners in public services: government relations in the modern welfare state. Baltimore: Johns Hopkins University Press, 1995.

SMITH, D. H. Four sectors or five? Retaining the member-benefit sector.

Nonprofit and voluntary sector quarterly, v. 20, n. 2, p. 137-50, Summer, 1991.

SOTERO, F. Gestão participativa em rede - GRP: descentralização e participação na gestão municipal. Brasília: 2002. Disponível em: http://alainet.org/active/show_text.php3?key=3061. Acessado em: 10 out. 2014.

STONER, J. A. F; FREEMAN, R. E. Administração. Rio de Janeiro: Prentice-Hall do Brasil, 1985.

TENÓRIO, F. Gestão de ONGs, principais funções gerenciais. Rio de Janeiro: FGV, 5 ed., 2001.

TEODÓSIO, A. S. S. Pensar o terceiro setor pelo avesso: dilemas e perspectivas da ação social organizada na gestão pública. In: ENCONTRO ANUAL DA ASSOCIAÇÃo NACIONAL DE PROGRAMAS DE PÓS-GRADUAÇÃo EM ADMINISTRAÇÃOENANPAD, XXV; 2001, Campinas. Anais... Campinas: ANPAD, 2001. 1 CD-ROM.

TEODÓSIO, A. S. S. Pensar pelo avesso o terceiro setor: mitos dilemas e perspectivas da ação social organizada nas políticas sociais. Lusotopie, 2002.

WEISBROD, B. Nonprofit economy. Cambridge: Harvard University Press, 1988. 